\title{
The French Guianan endemic Molossus barnesi (Chiroptera: Molossidae) is a junior synonym for $M$. coibensis
}

François Catzeflis $^{\mathrm{a}}$, Yann Gager ${ }^{\mathrm{b}, \mathrm{c}}$, Manuel Ruedi ${ }^{\mathrm{d}}$, and Benoit de Thoisy ${ }^{\mathrm{e}, \mathrm{f}}$

${ }^{a}$ Institut des Sciences de l'Evolution, Case Courrier 064, CNRS UMR-5554, Université Montpellier-2, Place E. Bataillon, F-34095 Montpellier, France, francois.catzeflis@univ-montp2.fr

${ }^{\mathrm{b}}$ Department of Migration and Immuno-Ecology, Max Planck Institute for Ornithology, 78315

Radolfzell, Germany, yann.gager@gmail.com

${ }^{c}$ Department of Biology, University of Konstanz, 78464 Konstanz, Germany

${ }^{\mathrm{d}}$ Department of Mammalogy and Ornithology, Natural History Museum of Geneva, BP 6434, 1211

Geneva 6, Switzerland, Manuel.Ruedi@ville-ge.ch

eLaboratoire des Interactions Virus-Hôtes, Institut Pasteur de la Guyane, 23 avenue Pasteur, BP 6010,

97306 Cayenne cedex, French Guiana, bdethoisy@pasteur-cayenne.fr

${ }^{\mathrm{f}}$ Association Kwata, 16 avenue Pasteur, 97300 Cayenne, French Guiana

Corresponding author: François Catzeflis

Keywords: Cryptic species - Morphometry - Nomenclature - French Guiana 


\section{Abstract}

2 The taxonomy of the small Neotropical Molossus species has been notoriously difficult due to a lack of

3 adequate comparative material. One taxon in particular, $M$. barnesi Thomas, 1905 was believed to be

4 restricted to a narrow stretch of coastal areas around Cayenne, in French Guiana and was so far

5 represented only by three female specimens. It was variously considered as a species on its own, or

6 synonymized with $M$. molossus or $M$. coibensis. Thanks to the discovery of several mixed colonies of

7 these small molossids in two localities in French Guiana, we could obtain and measure a large sample

8 (nearly 200 specimens) of adult individuals to better assess their morphological variation. Owing to

9 largely bimodal and non-overlapping distributions of external measurements such as forearm length,

10 we could demonstrate the existence of two sympatric morphotypes, the smaller one corresponding to

$11 M$. barnesi and the larger one to M. molossus. Univariate and multivariate comparisons of cranio-dental

12 and external characters further suggest that the new series of barnesi from French Guiana do not differ

13 notably from specimens assigned to $M$. coibensis from elsewhere. Molecular reconstruction based on

14 the barcode gene (CO1) confirmed their genetic distinctness, but also the overall close relationships

15 (mean divergence of $1.7 \%$ ) of all assayed taxa in this group. Although none of the haplotypes are

16 shared across taxa, haplotypes of $M$. coibensis from Panama and M. barnesi from French Guiana are

17 mixed in a single, poorly supported cluster, suggesting that these animals could represent a single

18 biological species. Based on all evidences, we thus recommend treating barnesi as a junior synonym of

19 M. coibensis, a species now widely and continuously distributed from Central America to Middle South 20 America.

\section{Introduction}

The Order Chiroptera represents one fifth of all extant Mammals with well over 1116 recognized species (Simmons, 2005), but the true diversity still remains underestimated in many places and taxonomic issues are continuously revised. Molecular data and phylogenetic reconstructions coupled with careful morphological comparisons provide an integrative framework that helps to better understand the evolution of this biodiversity and has been applied successfully in bat taxonomy (Goodman et al., 2009). We apply here such an integrative approach to resolve the taxonomic status of small Neotropical molossid bats of the genus Molossus.

Thomas (1905) described Molossus barnesi (Molossidae) from a single female specimen collected at Cayenne, French Guiana. Since then, this taxon was variously considered as a species on its own, or synonymized with other small Neotropical molossids. For instance, $M$. barnesi was synonymized with 
Eger (2008) rather classified it within M. coibensis (another small Molossus species originally described by Allen (1904) from the Island of Coiba, Panama). Although the first authors did not justify their taxonomic decision, Dolan compared the holotypes and considered that barnesi fell within the morphological variation of a series of Central American M. coibensis. More recently, Simmons and Voss (1998) caught two small Molossus during a large survey of mammals conducted at Paracou (ca. $80 \mathrm{~km}$ north-west from Cayenne), French Guiana. They also compared this new material with the holotype of barnesi and with several other small-sized Neotropical Molossus and showed that these new specimens corresponded well to barnesi. However, they concluded that M. barnesi was a taxon on its own and clearly distinct (generally smaller-sized and with different pelage and dental patterns) from any other recognized species, including $M$. coibensis or $M$. molossus. They also confirmed that $M$. barnesi was so far only known from these 2 localities in French Guiana.

Gregorin et al. (2011) challenged this taxonomic view arguing that the morphological characters distinguishing $M$. barnesi and $M$. coibensis were too variable in a broader geographic context or were overlapping between the few known $(\mathrm{n}=3)$ individuals of barnesi compared to the more numerous specimens assigned to M. coibensis. Gregorin et al. (2011) further mentioned the biogeographical issue regarding the much localized occurrence of barnesi (i.e. restricted to a small coastal area of French locality in the Atlantic Forest biome (Pimental et al., 2014).

As the source of most of these taxonomic controversies appears to be a lack of appropriate comparative material of M. barnesi, and because no DNA characters have been examined so far in this context, we report here the comparative morphological and molecular analyses of a series of new specimens of $M$. barnesi collected in two localities of French Guiana where this taxon lives in sympatry with typical populations of $M$. molossus. We also use DNA sequences of extralimital material of other small Neotropical Molossus species, including a series of $M$. coibensis, to reassess their taxonomic status.

\section{Material and methods}

Over 200 small molossid bats living under several tin roofs of traditional houses were caught at Remire-Montjoly between November and December 2007 (collectors Maël Dewynter and Julien Jemin) and at Cacao in July 2012 (collectors Francois Catzeflis and Manuel Ruedi), both locations being set along the coastal region of north-east French Guiana. The locality of Remire-Montjoly $\left(04^{\circ} 52^{\prime} 30^{\prime \prime} \mathrm{N} ; 52^{\circ} 16^{\prime} 30^{\prime \prime} \mathrm{W}\right)$ lies in the eastern suburbs adjacent to the city of Cayenne, with surrounding habitats highly anthropized and consisting of a patchwork of private houses, gardens, and 
small forest fragments. The locality of Cacao $\left(04^{\circ} 34^{\prime} 30^{\prime \prime} \mathrm{N} ; 52^{\circ} 27^{\prime} 10^{\prime \prime} \mathrm{W}\right)$ lays ca. $45 \mathrm{~km}$ to the south of Cayenne and is set in an agricultural landscape comprised of various orchards and small plots of organic vegetables, with some secondary forest remains in its immediate vicinity.

Capture methods included mist nets $(2.6 \times 6 \mathrm{~m}$ and $2.6 \times 9 \mathrm{~m}$; mesh size $=16 \mathrm{~mm})$ set close to the edges of roofs from where the molossids were leaving their roost at dusk. Upon capture, bats were held temporarily in individual cotton bags. Prior to release, each animal was aged (only adults with completely fused phalangeal epiphyses were considered), sexed and measured for the following three external measurements (with a dial calliper to the nearest $0.1 \mathrm{~mm}$ ): forearm length (FA; taken from the tip of the elbow to the wrist with the wing held closed), length of metacarpal of third (MC3) and of fourth digit (MC4; measured on the dorsal side of the wing held flat on a solid surface, from the basis of the wrist to the tip of the metacarpal). A selection of 50 specimens (see list in Appendix A) were kept and euthanized following the guidelines of the American Society of Mammalogists for the use of wild mammals in research (Sikes and Gannon, 2011). These specimens were preserved as scientific vouchers for further morphological and genetic analyses. A fragment of chest muscle was kept in $95 \%$ ethanol and specimens were fixed for one day in $10 \%$ buffered formalin, and stored in $70 \%$ ethanol. As no specific decree conserving bats outside protected areas exist in French Guiana, no specific legal authorization was required for captures and handling of bats.

\section{Morphology}

Reproductive status was acquired from external characteristics (e.g. enlarged nipples or testis) or from gross examination of dissected specimens (Racey, 2009). In addition to the three external characters taken on all bats (FA, MC3 and MC4), tibia length (TI), tail length (TL), wingspan (WS), weight (expressed in grams) and length of mid-dorsal fur (DF) were also recorded on each vouchered specimen. Nine cranio-dental measurements were taken on the cleaned skulls with a dial calliper (accurate to $0.05 \mathrm{~mm}$ ) following the methods detailed in Simmons and Voss (1998) except when noted: greatest length of skull (bone-to-bone: GLS), maxillary toothrow length (MTL), condylo-incisive length (CIL), breadth across canines $(\mathrm{BaC})$, zygomatic breadth $(\mathrm{ZB})$, mastoid breadth $(\mathrm{MB})$, braincase breadth $(\mathrm{BB})$, post-orbital breadth $(\mathrm{PB})$ and outer breadth across molars (BaM). Because sexual dimorphism is common in Molossidae, including in the genus Molossus (Freeman, 1981; Willig and Hollander, 1995), we determined its significance with Mann-Whitney tests (as implemented in the software PAleontological STatistics: Hammer et al., 2001). As most historic specimens are females and also to avoid the confounding factor of sexual dimorphism, the following global morphological comparisons were based only on a subset of 48 female molossids. This subset included $21 \mathrm{M}$. barnesi from French Guiana (including the two females studied by Simmons and Voss, 1998), 19 M. molossus from French Guiana (including nine specimens studied by Simmons and Voss, 1998), the holotype of 
M. barnesi (BMNH-5.1.8.7, at the London Natural History Museum) and a series of seven females of M. coibensis from Brazil (Universidade Federal do Pará Campus de Bragança: vouchers numbers LJCC-13, LJCC-14, LJCC-16 to -20) assigned to this taxon by Correa da Costa et al. (2013).

110 Morphological shape variation, determined for six cranial (GLS, CIL, MTL, BaM, BB, and PB) and 111 one external (FA) measurements, was analysed using a Principal Component Analysis Biplot on scaled 112 data (PCA Biplot, R Core Team, 2015).

Molecular analyses

115 DNA was extracted with the NucliSENS EasyMag robot (Biomérieux, Craponne, France) following 116 manufacturer's recommendations for tissue extraction. The barcoding fragment of the mitochondrial 117 gene Cytochrome oxydase 1 (CO1) was amplified as recommended by Borisenko et al. (2008). After amplification, PCR products were sent for purification and sequencing at Cogenics (Takeley, UK), using the same primers as for amplifications. Of the ca. one hundred sequences of small Molossus already available in GenBank, we selected a subset of 15 distinct haplotypes to represent 1 or 2 individuals each of the taxa coibensis, molossus and rufus living in the areas of sympatry (Panama, Ecuador and the Guiana Shield). Together with these 15 sequences retrieved from GenBank (Accession numbers in Appendix B), the six sequences generated here were aligned and checked manually with MEGA 6.0 (Tamura et al., 2013) for absence of gaps or stop codons, to ensure that these were not pseudogenes.

Phylogenetic relationships between samples were evaluated with neighbour-joining (NJ), maximum likelihood (ML) and Bayesian procedures, and using two Eumops species (two exemplars each of $E$. hansae and E. auripendulus - accession numbers in Appendix B) as outgroups. The Tamura-Nei model (TN93) with gamma $(\mathrm{G})$ rate parameter and a proportion of invariant sites (I) was identified with MEGA 6.0 as the best-fitting nucleotide substitution model. Ten thousand replicates were used for maximum likelihood and neighbour-joining analyses, yielding support values as Bootstrap Percentage (BP). The Bayesian approach was carried out with MrBAYES 3.2 (Ronquist et al., 2012). Markov Chain Monte Carlo (MCMC) simulations were run twice independently for 10 million generations with four simultaneous chains, using a sample frequency of one every 1,000 and a burn-in of 3 million trees. Support values are indicated as Posterior Probabilities (PP) and were calculated from the remaining trees. Together with the phylogenetic trees, we estimated the haplotype network of Molossus spp. sequences using Network 4.5.0. and the Median Joining (MJ) network algorithm (Bandelt et al., 1999). 
143 Capture sessions at Remire-Montjoly and Cacao yielded 196 adult Molossus bats. We plotted the 144 distribution of FA lengths measured in these colonies for each sex separately. Measurements of the 128 145 females (53 from Remire-Montjoly and 75 from Cacao) and 68 males ( 27 and 41, respectively) show 146 clear bimodal distributions, with little or no overlap between the two morphotypes found in syntopy 147 (Figure 1). According to these clear differences, all females with a forearm smaller than $37.1 \mathrm{~mm}$ and 148 all males with a FA smaller than $37.4 \mathrm{~mm}$ were assigned to the $M$. barnesi morphotype, whereas the 149 larger specimens were assigned to M. molossus, as suggested by Simmons and Voss (1998). As expected, all other external measurements correlated with size differed significantly between those two species identified by their forearm size (Table 1). Intraspecific sexual dimorphism, whereby males are

152 larger than females, was also significant in the digit measurements (MC3 and MC4) of M. barnesi but 153 not in those of M. molossus, as shown in Table 2.

Cranio-dental measurements also revealed the existence of a significant overall sexual dimorphism ( $\mathrm{p}<$ 0.01), with males being larger that female at most variables (GLS, CIL, ZB, MB, BB and BaC). Significant intraspecific sexual dimorphism was also evident in the skulls of both species $(\mathrm{p}<0.01$ for all variables except BaM in M. barnesi, and except MTL and PB in M. molossus). Regardless of the sex, skulls of M. molossus were longer than in M. barnesi, with all antero-posterior measurements (GLS, CIL, MTL, PB) being significantly different $(\mathrm{p}<0.01)$, whereas these two taxa had similar skull breadth (as measured by ZB, MB, BaM, BB, BaC; $\mathrm{p}>0.05$; Table 3 ).

An analysis of variance (ANOVA) for size variation at one external (FA) and six cranio-dental measurements (GLS, CIL, MTL, BaM, BB, and PB) of the 48 female reference specimens indicates that $M$. molossus is clearly larger than $M$. barnesi and $M$. coibensis (post-hoc Tuckey test: $\mathrm{p}=0.0001$ and $\mathrm{p}=0.0323$, respectively), while females $M$. coibensis and $M$. barnesi do not differ significantly ( $\mathrm{p}$ $=0.7998)$. The PCA Biplot based on those same variables explained a high percentage of the total variation, $45.5 \%$ being associated to the first and $26.0 \%$ to the second component. This PCA Biplot indicates that the seven M. coibensis from Brazilian Para and all specimens of M. barnesi from French Guiana (including the holotype of barnesi) form completely overlapping groups, while individuals of M. molossus are set in a distinct cluster (Figure 2).

172 Table 4 compares our French Guianan sample consisting of 11 males and 20 females (including the 173 holotype) $M$. barnesi with a sample of 21 males (including the type of coibensis) and 23 females $M$. 174 coibensis taken in Panama (sample \#19 from Chiriquí, La Concepcíon, in Dolan, 1989). As already mentioned by Dolan (1989), measurements of the female holotype of barnesi (BMNH-5.1.8.7) fall within the range of female specimens of $M$. coibensis from Central America. Similarly, the male holotype of coibensis (AMNH-18731) conforms well to the variation of males M. coibensis from 
The phylogenetic reconstructions (Figure 3 - left panel) based on CO1 sequences indicate that small Molossus assayed form various monophyletic clades which appear very closely related to each other, differing by an average of $1.7 \%$ substitutions (range $0.0-2.0 \%$ ). In particular, sequences of $M$. coibensis from Ecuador and Panama and those of M. barnesi from French Guiana differ by less than $1.5 \%$ substitutions. Sequences of M. molossus from French Guiana, Ecuador, Panama, Suriname and Guyana and those of M. rufus from French Guiana and Guyana each form monophyletic taxa (BP support $71 \%$ and $95 \%$, respectively), whereas sequences of $M$. coibensis and M. barnesi are intertwined. The MJ network which shows in more details relationships of the various haplotypes (Figure 3 - right panel) further indicates that the COI haplotypes of $M$. barnesi and $M$. coibensis derive from the same haplogroup, whereas those of M. molossus and $M$. rufus are set further apart.

\section{Discussion}

192 The newly collected material of $M$. barnesi sampled close to the type-locality in French Guiana adds to the only three historical specimens (all females) reported so far by Simmons and Voss (1998). The now enlarged samples provide an appropriate series for assessing morphological variation and sexual dimorphism in this highly localized taxon. In two different localities (Cacao and Rémire-Montjoly), these small molossids were captured in strict sympatry (i.e. under the same tin roof) with another, larger species (M. molossus). It is, however, unclear whether individuals live really in intermixed clusters or whether they form species-specific social groups occupying different portions of the same building. According to the principle of competitive exclusion verified in other sibling species of bats living in sympatry (Arlettaz et al., 1997), these two species should even differ at some ecological aspects but this has still to be ascertained with proper evidences. Synanthropic roosts occupied simultaneously by 2 or 3 species of small molossids were also reported in the Brazilian Atlantic Forest (M. molossus, M. coibensis, M. rufus) by Pimenta et al. (2014) and in central Panama (M. molossus, $M$. coibensis, and M. bondae) by Gager et al. (2016), whereas the syntopic occurrence of $M$. coibensis and M. molossus in outside roosts is already known from Ecuador (McDonough et al., 2011), from Guyana (Lim and Engstrom, 2001) and from Brazil (Pimenta et al., 2014).

Despite more of less pronounced sexual dimorphism exhibited by both species, highly significant morphometric differences exist between the distinctly smaller M. barnesi versus the larger M. molossus in French Guiana. This clearly supports the taxonomic distinction proposed by Simmons and Voss (1998). In particular, wing measurements (FA, MC3, MC4 and WS) are all very discriminant, with little or no overlap between those two sympatric species. Our large samples of both Molossus species in French Guiana further show that the sexual dimorphism is more pronounced in M. barnesi than in $M$. 
213 molossus, as illustrated by external measurements such as forearm or third and fourth metacarps. Due

214 to an overall significant sexual dimorphism (males being generally larger than females), these external

215 differences are even more obvious when values are sorted by sex, as detailed in Table 2. Another

216 external character mentioned by Simmons and Voss (1998), i.e. the length of dorsal hairs measured in

217 the mid-dorsum (DF), is less useful for the discrimination of both species because several individuals

218 caught in sympatry in French Guiana and in south-east Brazil (Pimenta et al., 2014) had intermediate

219 values (about $3.0 \mathrm{~mm}$ ).

220 Regarding the cranio-dental variables, we observed that $M$. barnesi and M. molossus have similar 221 measurements in the breadth of the skull (expressed by ZB, MB, BaM, BB or BaC) but differ for length 222 measurements (i.e. GLS, CIL, MTL or PB). Thus, the skull of M. barnesi is relatively shorter than that 223 of M. molossus for similar breadth. This difference again corroborates earlier remarks on skull shape 224 mentioned for those two species in Brazil (Pimenta et al., 2014). Another qualitative discriminant 225 character proposed by Simmons and Voss (1998) and also noted by Pimenta et al. (2014) is the shape 226 of the upper incisors (Figure 3). The six illustrated specimens indeed show that M. barnesi have 227 slightly shorter and more convergent (spatulate) upper incisors, whereas those of M. molossus are more 228 elongated and tapering (pincer-like), but these qualitative differences are sometimes difficult to 229 evaluate on single specimens.

230 Although various morphological and morphometric characters support the existence of three distinct 231 species of Molossus living in sympatry in French Guiana (the small M. barnesi and M. molossus and 232 the much larger M. rufus, Simmons and Voss, 1998), their CO1 sequences are very similar (differing 233 by about $1.7 \%$ nucleotides substitutions), indicating that these haplotypes derive from a recent common 234 mitochondrial ancestor. None of the sequenced bats shared the same haplotype (Figure 3 - right panel) 235 but the number of assayed individuals here is not enough to establish firmly if time since their 236 separation was long enough to lead to reciprocal monophyly of lineages in each species. When other 237 extralimital sequences of other small Molossus are included in the molecular analyses, notably those of 238 M. coibensis from Ecuador and Panama, the separation of taxa does not improve, as sequences are 239 globally all very closely related (Figure 3). This indicates that most mitochondrial lineages in this 240 group diverged recently from each others. Based on a much larger data set, Gager et al. (2016) also 241 found very closely related CO1 sequences between morphologically distinct $M$. coibensis and $M$. 242 molossus from Panama, Ecuador, Guyana and Suriname. Whereas the usefulness of DNA barcoding 243 has proven its effectiveness in several other studies of bat identification (e.g. Clare et al., 2007, 2011; 244 Lim, 2012), this example of morphologically recognizable taxa which do not show necessarily 245 appreciable genetic differentiation indicates that more rapidly evolving genes (such as some fast246 evolving nuclear introns or the mitochondrial control region) might be necessary to reach a better 247 phylogenetic resolution. 
248 Even if barcodes are of limited use in this group (Borisenko et al., 2008), haplotypes of M. barnesi

249 from French Guiana are intertwined with those of geographically more distant M. coibensis from

250 Panama and Ecuador and do not form distinct haplogroups (Figure 3). Notably, the later include

251 representative sequences of $M$. coibensis sampled close to the type-locality of this taxon in Panama and 252 identified with multiple morphological, bioacoustics and molecular characters (Gager et al., 2016).

253 Again, such close genetic relatedness and lack of reciprocal monophyly calls into question the 254 taxonomic distinctness of these two taxa.

255 Based on our new univariate and multivariate morphological comparisons, we further demonstrate that 256 animals assigned to M. coibensis from Brazil (Correa da Costa et al., 2013) and to M. barnesi from 257 French Guiana are indistinguishable, whereas all M. molossus are clearly set apart on this morphospace 258 (Figure 2). Although none of the specimens of $M$. coibensis from near the type-locality in Panama 259 could be added to this multivariate analysis, measurements of the type specimen (Table 4) and direct 260 morphological comparisons made by earlier researchers (Dolan, 1989; Eger, 2008; Gregorin et al., 261 2011) also confirm that coibensis and barnesi cannot be distinguished elsewhere. Given all available genetic and morphologic evidences, we thus recommend to consider M. barnesi as a junior synonym of M. coibensis. This proposed synonymy would also solve the critical issue raised by Gregorin et al. (2011) concerning the apparent lack of M. coibensis in some areas of the Guiana Shield (Lim and 265 Tavares, 2012), whereas it is found further south to the Mato Grosso and the Atlantic Forest biome in 266 Brazil (Paglia et al., 2012; Correa da Costa et al., 2013; Pimenta et al., 2014). Given the anthropophilous character of the species in French Guiana (reported so far as M. barnesi) and elsewhere, we anticipate that more localities of $M$. coibensis throughout South America will fill gaps between the current scattered occurrences for this species. In conclusion, we concur with Gregorin et al. (2011) that a more global taxonomic review concerning other small taxa of the genus Molossus living in tropical South America is needed, as the exact number of distinct biological species contained 272 in this group is still debated. Unusually divergent barcode sequences of a small Molossus sp. found in 273 the Kanuku Mountains of Guyana (Lim and Engstrom, 2001) even suggest that additional cryptic 274 species might occur in the region (Clare et al., 2007).

\section{Acknowledgements}

277 We first would like to acknowledge Maël Dewynter and Julien Jemin for generously sharing their data 278 on the molossids which they caught at Remire-Montjoly as well as Julien Claude for helping with some 279 statistical analyses of morphological variation. Laurent Vallotton provided appreciated help in the field 280 in Cacao. Skulls were prepared by Michel Gillioz at the Natural History Museum of Geneva 281 (Switzerland). The study received financial support from the Agence Nationale de la Recherche 282 through an "Investissement d'Avenir" grant (CEBA, ref. ANR-10-LABX-25-01). Fieldwork at Cacao 
283 (French Guiana) was funded by French National Research Agency Project ANR 06-SEST-20 IAEL 284 attributed to the MIVEGEC (UMR IRD 224-CNRS 5290) laboratory of Montpellier, France. 285 286 


\section{References}

Allen, J.A., 1904. New bats from tropical America, with note on species of Otopterus. Bull. Am. Museum Nat. Hist. 20, 227-237.

Arlettaz, R., Perrin, N., Hausser, J., 1997. Trophic resource partitioning and competition between the two sibling bat species Myotis myotis and Myotis blythii. J. Anim. Ecol. 66, 897-911.

Bandelt, H.J., Forster, P., Rohl, A., 1999. Median-joining networks for inferring intraspecific phylogenies. Mol. Biol. Evol. 16, 37-48.

Borisenko, A. V, Lim, B.K., Ivanova, N. V, Hanner, R.H., Hebert, P.D.N., 2008. DNA barcoding in surveys of small mammal communities: a field study in Suriname. Mol. Ecol. Resour. 8, 471-9. doi:10.1111/j.1471-8286.2007.01998.x

Brosset, A., Charles-Dominique, P., 1990. The bats of French Guiana: a taxonomic, faunistic and ecological approach. Mammalia 54, 509-560.

Clare, E.L., Lim, B.K., Engstrom, M.D., Eger, J.L., Hebert, P.D.N., 2007. DNA barcoding of Neotropical bats: species identification and discovery within Guyana. Mol. Ecol. Notes 7, 184-190. doi:10.1111/j.1471-8286.2006.01657.x

Correa da Costa, L.J., Gonçalves de Andrade, F.A., Uieda, W., Gregorin, R., Barroncas Fernandes, M.E., 2013. First record of Molossus coibensis (Chiroptera: Molossidae) in the Brazilian Amazon. Mastozool. Neotrop. 20, 143-147.

Dolan, P.G., 1989. Systematics of Middle American mastiff bats of the genus Molossus. Spec. Publ. Museum Texas Tech Univ. 29, 1-71.

Eger, J.L., 2008. Family Molossidae, in: Gardner, A.L. (Ed.), Mammals of South America Marsupials, Xenarthrans, Shrews, and Bats, Vol. 1. The University of Chicago Press, Chicago and London, pp. $399-440$.

Freeman, P.W., 1981. A multivariate study of the family Molossidae (Mammalia, Chiroptera) : Morphology, ecology, evolution. Fieldiana Zool. 7, 1-173.

Gager, Y., Tarland, E., Lieckfeldt, D., Ménage, M., Botero-Castro, F., Rossiter, S. J., Kraus, R. H. S., Ludwig, A., Dechmann, D. K. , 2016. The value of molecular vs morphometric and acoustic information for species identification using sympatric molossid bats. PLoS ONE 11 (3) : e0150780.doi:10.1371/journal.pone.0150780 
Goodman, S.M., Maminirina, C.P., Weyeneth, N., Bradman, H.M., Christidis, L., Ruedi, M., Appleton, B., 2009. The use of molecular and morphological characters to resolve the taxonomic identity of cryptic species: the case of Miniopterus manavi (Chiroptera, Miniopteridae). Zool. Scr. 38, 339-363. doi:10.1111/j.1463-6409.2008.00377.x

Gregorin, R., Tahara, A.S., Buzzato, D.F., 2011. Molossus aztecus and other small Molossus (Chiroptera: Molossidae) in Brazil. Acta Chiropterologica 13, 311-317.

doi:10.3161/150811011X624794

Hammer, Ø., Harper, D.A.T., Ryan, P.D., 2001. PAST: Paleontological statistics software package for education and data analysis. Palaeontol. Electron. 4, 1-9.

Lim, B.K., Engstrom, M.D., 2001. Species diversity of bats (Mammalia: Chiroptera) in Iwokrama Forest, Guyana, and the Guianan subregion: implications for conservation. Biodivers. Conserv. 10, 613-657. doi:10.1023/A:1016660123189

Lim, B.K., Tavares, V. da C., 2012. Review of species richness and biogeography of bats (Chiroptera) from the Guiana subregion of South America with comments on conservation. Ecotropica 18, 105-118.

Paglia, A.P., Fonseca, G.A.B. da Rylands, A.B., Herrmann, G., Aguiar, L.M.S., Chiarello, A.G., Leite, Y.L.R., Costa, L.P., Siciliano, S., Kierulff, M.C.M., Mendes, S.L., Tavares, V. da C. Mittermeier, R.A., Patton J. L., 2012. Annotated checklist of Brazilian mammals. Occas. Pap. Conserv. Biol. 6, 1-76.

Pimenta, V., Fonseca, B. S., Hoppe, J. P., Ditchfield, A. D., 2014. First occurrence of Molossus coibensis Allen, 1904 (Chiroptera, Molossidae) in Atlantic Forest. Chiroptera Neotropical 20, 1237 1242.

R Core Team, 2015. R: A language and environment for statistical computing.

Racey, P.A., 2009. Reproductive assessment of bats, in: Kunz, T.H., Parsons, S. (Eds.), Ecological and Behavioral Methods for the Study of Bats. Johns Hopkins University Press, Baltimore, USA, pp. 249264.

Ronquist, F., Teslenko, M., van der Mark, P., Ayres, D.L., Darling, A., Höhna, S., Larget, B., Liu, L., Suchard, M.A., Huelsenbeck, J.P., 2012. MrBayes 3.2: efficient Bayesian phylogenetic inference and model choice across a large model space. Syst. Biol. 61, 539-42. doi:10.1093/sysbio/sys029

Sikes, R.S., Gannon, W.L., 2011. Guidelines of the American Society of Mammalogists for the use of wild mammals in research. J. Mammal. 92, 235-253. doi:10.1644/10-MAMM-F-355.1 
Simmons, N.B., 2005. Order Chiroptera, in: Wilson, D.E., Reeder, D.M. (Eds.), Mammal Species of the World: A Taxonomic and Geographic Reference. Johns Hopkins University Press, pp. 312-529.

Simmons, N.B., Voss, R.S., 1998. The mammals of Paracou, French Guiana, a Neotropical lowland rainforest fauna. Part 1, Bats. Bull. Am. Museum Nat. Hist. 237, 219.

Tamura, K., Stecher, G., Peterson, D., Filipski, A., Kumar, S., 2013. MEGA6: Molecular Evolutionary Genetics Analysis version 6.0. Mol. Biol. Evol. 30, 2725-9. doi:10.1093/molbev/mst197

Thomas, O., 1905. New Neotropical Molossus, Conepatus, Nectomys, Proechimys, and Agouti, with a note on the genus Mesomys. Ann. Mag. Nat. Hist. 15, 584-591. doi:10.1080/03745480509442857

Willig, M.R., Hollander, R.R., 1995. Secondary sexual dimorphism and phylogenetic constraints in bats: A multivariate approach. J. Mammal. 76, 981-992. doi:10.2307/1382592 


\section{Tables}

Table 1. External measurements for small molossids caught in syntopy at Remire-Montjoly and Cacao, in French Guiana. All females with a forearm smaller than $37.1 \mathrm{~mm}$ and all males with a forearm smaller than $37.4 \mathrm{~mm}$ were assigned to the M. barnesi morphotype, whereas the larger specimens were assigned to M. molossus. Values are mean \pm one standard-deviation (minimum and maximum); $\mathrm{n}=$ sample size. See Material and Methods for abbreviations of measurements. W stands for weight, expressed in grams, while all other variables are expressed in $\mathrm{mm}$.

\begin{tabular}{|c|c|c|c|c|}
\hline & M. barnesi & $\mathrm{n}$ & M. molossus & $\mathrm{n}$ \\
\hline FA & $\begin{array}{c}35.1 \pm 0.9 \\
(32.9-37.3)\end{array}$ & 142 & $\begin{array}{c}39.1 \pm 1.0 \\
(37.3-41.6)\end{array}$ & 54 \\
\hline MC3 & $\begin{array}{c}34.2 \pm 0.9 \\
(32.0-36.0)\end{array}$ & 127 & $\begin{array}{c}38.6 \pm 1.2 \\
(36.0-41.5)\end{array}$ & 48 \\
\hline MC4 & $\begin{array}{c}32.5 \pm 0.9 \\
(30.0-34.5)\end{array}$ & 127 & $\begin{array}{c}36.6 \pm 1.0 \\
(34.0-39.5)\end{array}$ & 48 \\
\hline TL & $\begin{array}{c}32.9 \pm 1.6 \\
(28.0-36.5)\end{array}$ & 60 & $\begin{array}{c}37.3 \pm 2.0 \\
(33.0-40.0)\end{array}$ & 16 \\
\hline $\mathrm{TI}$ & $\begin{array}{c}12.6 \pm 0.5 \\
(11.5-13.5)\end{array}$ & 60 & $\begin{array}{c}13.8 \pm 0.5 \\
(13.0-15.0)\end{array}$ & 17 \\
\hline WS & $\begin{array}{c}260.7 \pm 7.39 \\
(248.0-280.0)\end{array}$ & 47 & $\begin{array}{c}300.5 \pm 11.3 \\
(280.0-322.0)\end{array}$ & 15 \\
\hline DF & $\begin{array}{c}2.5 \pm 0.3 \\
(2.0-3.0)\end{array}$ & 12 & $\begin{array}{c}3.1 \pm 0.2 \\
(3.0-3.5)\end{array}$ & 7 \\
\hline $\mathrm{W}$ & $\begin{array}{c}11.5 \pm 1.9 \\
(7.8-16.3)\end{array}$ & 53 & $\begin{array}{c}13.1 \pm 1.6 \\
(9.5-16.0)\end{array}$ & 20 \\
\hline
\end{tabular}


Table 2. Three wing measurements (FA, MC3, MC4) of small Molossus spp. caught in syntopy at the localities of Remire-Montjoly and Cacao in French Guiana. Values (in mm) are expressed as the mean \pm one standard deviation (minimum - maximum); $\mathrm{n}=$ sample size. The $\mathrm{p}$ value of the last column represents the significance of sexual dimorphism investigated with Mann-Whitney tests.

\begin{tabular}{|c|c|c|c|c|c|}
\hline & \multicolumn{4}{|c|}{ M. barnesi } & \multirow[b]{2}{*}{$\mathrm{p}$} \\
\hline & females & $\mathrm{n}$ & males & $\mathrm{n}$ & \\
\hline FA & $\begin{array}{c}34.8 \pm 0.7 \\
(32.9-36.3)\end{array}$ & 95 & $\begin{array}{c}35.9 \pm 0.7 \\
(33.9-37.3)\end{array}$ & 47 & $<0.0001$ \\
\hline $\mathrm{MC} 3$ & $\begin{array}{c}34.0 \pm 0.8 \\
(32.0-35.5)\end{array}$ & 83 & $\begin{array}{c}34.6 \pm 0.8 \\
(32.5-36.0)\end{array}$ & 44 & $<0.0001$ \\
\hline \multirow[t]{3}{*}{$\mathrm{MC} 4$} & $\begin{array}{c}32.4 \pm 0.9 \\
(30.0-34.5)\end{array}$ & 83 & $\begin{array}{c}32.8 \pm 0.9 \\
(31.0-34.5)\end{array}$ & 44 & 0.0204 \\
\hline & \multicolumn{4}{|c|}{ M. molossus } & \\
\hline & females & $\mathrm{n}$ & males & $\mathrm{n}$ & $\mathrm{p}$ \\
\hline FA & $\begin{array}{c}39.0 \pm 0.8 \\
(37.3-40.8)\end{array}$ & 33 & $\begin{array}{c}39.4 \pm 1.2 \\
(37.4-41.6)\end{array}$ & 21 & 0.4087 \\
\hline MC3 & $\begin{array}{c}38.8 \pm 1.2 \\
(36.0-41.5)\end{array}$ & 29 & $\begin{array}{c}38.4 \pm 1.2 \\
(37.0-40.5)\end{array}$ & 19 & 0.2479 \\
\hline MC4 & $\begin{array}{c}36.6 \pm 0.9 \\
(34.0-38.0)\end{array}$ & 29 & $\begin{array}{c}36.6 \pm 1.2 \\
(35.0-39.5)\end{array}$ & 19 & 0.3813 \\
\hline
\end{tabular}


Table 3. Mean, standard deviation and ranges of 9 cranio-dental measurements (expressed in $\mathrm{mm}$ ) taken on skulls of M. barnesi $(\mathrm{n}=30)$ and M. molossus $(\mathrm{n}=20)$ caught in syntopy in French Guiana. Males and females were not distinguished. Significance of differences was investigated with MannWhitney ( $\mathrm{p}$ values). See Material and Methods for abbreviations of these cranio-dental variables.

\begin{tabular}{lccc}
\hline & M. barnesi & M. molossus & $\mathrm{p}$ \\
\hline & & & \\
GLS & $16.1 \pm 0.6$ & $16.6 \pm 0.7$ & 0.0078 \\
& $(15.4-17.5)$ & $(15.5-17.9)$ & \\
CIL & $14.9 \pm 0.5$ & $15.7 \pm 0.5$ & $<0.0001$ \\
& $(14.2-15.9)$ & $(14.5-16.3)$ & \\
ZB & $10.6 \pm 0.3$ & $10.5 \pm 0.4$ & 0.9420 \\
& $(10.1-11.2)$ & $(9.8-11.2)$ & \\
MB & $10.2 \pm 0.5$ & $10.1 \pm 0.4$ & 0.5438 \\
& $(9.3-11.1)$ & $(9.4-10.9)$ & \\
MTL & $5.9 \pm 0.2$ & $6.2 \pm 0.2$ & $<0.0001$ \\
& $(5.5-6.3)$ & $(5.6-6.5)$ & \\
BaM & $7.6 \pm 0.2$ & $7.6 \pm 0.3$ & 0.3233 \\
& $(7.2-8.1)$ & $(7.0-8.1)$ & \\
PB & $3.8 \pm 0.1$ & $3.6 \pm 0.2$ & 0.0011 \\
& $(3.5-4.1)$ & $(3.3-4.0)$ & \\
BB & $8.9 \pm 0.2$ & $8.8 \pm 0.3$ & 0.0721 \\
& $(8.5-9.2)$ & $(8.4-9.3)$ & \\
BaC & $4.3 \pm 0.2$ & $4.4 \pm 0.2$ & 0.0537 \\
& $(4.0-4.6)$ & $(4.0-4.8)$ & \\
& & & \\
\hline
\end{tabular}


Table 4. Selected external and cranio-dental measurements (in mm) indicating that Molossus barnesi is morphometrically similar to M. coibensis. Values of M. barnesi are for 30 French Guianan individuals from Cacao and Remire-Montjoly; values of M. coibensis are for 43 Panamanian individuals from Chiriquí (La Concepcíon), corresponding to population sample-19 in Dolan (1989). The values for the holotypes of M. barnesi (BMNH-5.1.8.7) and M. coibensis (AMNH-18731) are taken from Table 64 in Simmons and Voss (1998). Values are mean \pm standard-deviation (minimum and maximum); $\mathrm{n}=$ sample size. Abbreviations GLS, MTL, BB, BaM: see text in Material and Methods; NA = Not Available.

Males M. coibensis

Males M. barnesi

Holotype M. coibensis

Females M. coibensis

Females M. barnesi

Holotype M. barnesi

Males M. coibensis

Males M. barnesi

Holotype M. coibensis

Females M. coibensis

Females M. barnesi

Holotype M. barnesi

Males $M$. coibensis

Males M. barnesi

Holotype M. coibensis

Females $M$. coibensis

Females M. barnesi

Holotype M. barnesi
Forearm length

$36.0 \pm 0.6(34.8-36.8) \mathrm{n}=20$

$36.0 \pm 1.0(33.9-37.3) n=11$

35.5

$34.7 \pm 0.5(33.6-35.6) \mathrm{n}=23$

$35.0 \pm 0.6(33.8-36.1) \mathrm{n}=19$

33.8

GLS

$17.7 \pm 0.3(17.2-18.0) \mathrm{n}=19$

$16.7 \pm 0.5(16.0-17.5) \mathrm{n}=11$

15.9

$16.7 \pm 0.2((16.4-17.1) n=16$

$15.7 \pm 0.2(15.4-16.3) n=19$

16.6

BB

$9.1 \pm 0.2(8.8-9.5) n=19$

$9.0 \pm 0.1(8.8-9.2) n=11$

8.4

$8.9 \pm 0.1(8.7-9.1) n=16$

$8.8 \pm 0.2(8.5-9.2) n=19$

8.8
$7.7 \pm 0.2(7.3-7.9) n=16$

Tail length

$4.6 \pm 1.7(31.0-37.0) n=18$

$3.7 \pm 1.2(32.0-35.5) \mathrm{n}=9$

NA

$1.8 \pm 1.8(28.0-34.0) n=16$

$2.0 \pm 1.4(30.0-35.0) \mathrm{n}=17$

31.0

MTL

$6.2 \pm 0.1(5.9-6.4) n=19$

$6.0 \pm 0.1(5.8-6.3) n=11$

6.0

$5.9 \pm 0.1(5.7-6.1) n=16$

$5.8 \pm 0.1(5.5-6.0) n=19$

5.9

BaM

$8.0 \pm 0.2(7.7-8.2) \mathrm{n}=18$

$7.7 \pm 0.2(7.4-8.1) n=11$

8.0

$7.5 \pm 0.2(7.2-7.8) n=19$

7.3 


\section{Appendices}

Appendix A. Examined material. Animals sequenced for the $\mathrm{CO} 1$ barcoding gene are indicated with hashtag (\#). Molossus barnesi - French Guiana: Roura: Cacao: MHNG-1983.014, 1983.015, 1983.020\#, 1983.022; 1984.007; 1984.011 to 1984.013; Régina: Kaw-Roura: MHNG-1894.004\#; Remire-Montjoly: MHNG-1979.023 to $1979.032,1979.034,1979.035 ; 1984.061$ to 1984.068 , 1984.072, 1984.073. Molossus molossus - French Guiana: Roura: Cacao: MHNG-1972.019 to $1972.024 ; 1983.016,1983.017,1983.019 \#, 1983.023$ to $1983.025 ; 1984.008 \#$ to $1984.010,1984.014$ to 1984.016; Remire-Montjoly: MHNG-1979.033. Molossus rufus - French Guiana: Régina: Nouragues MHNG-1880.046\#. 
Appendix B. List of animals with CO1 barcoding fragment: 15 individuals retrieved from GenBank and 6 individuals (indicated with §) sequenced for this study. Abbreviations for specimen numbers: MHNG = Muséum d'histoire naturelle de Genève (Switzerland); ROM = Royal Ontario Museum (Toronto, Canada). The column "Haplotype" provides the haplotype number for animals of the MJ network of right panel in Figure 3.

\begin{tabular}{|c|c|c|c|c|}
\hline Taxon & Specimen & GenBank & Locality & $\begin{array}{l}\text { Hapl- } \\
\text { otype }\end{array}$ \\
\hline Eumops auripendulus & ROM-103160 & EF080347 & Guyana: Upper Takutu-Upper Essequibo & - \\
\hline Eumops auripendulus & MHNG-1939.069 & KU737546 \& & French Guiana: Régina: Kaw & - \\
\hline Eumops hansae & ROM-109153 & EF080356 & Guyana: Potaro-Siparuni & - \\
\hline Eumops hansae & ROM-109310 & EF080357 & Guyana: Potaro-Siparuni & - \\
\hline Molossus barnesi & MHNG-1894.004 & KU737547 § & French Guiana: Régina: Kaw & 6 \\
\hline Molossus barnesi & MHNG-1983.020 & KU737549 $\S$ & French Guiana: Roura: Cacao & 7 \\
\hline Molossus coibensis & ROM-105638 & JF448088 & Ecuador: Napo, Parque Nacional Yasuni & 5 \\
\hline Molossus coibensis & ROM-105303 & JF448947 & Ecuador: Napo, Parque Nacional Yasuni & 5 \\
\hline Molossus coibensis & Not preserved & KT721383 & Panama: Gamboa & 1 \\
\hline Molossus coibensis & Not preserved & KT721396 & Panama: Gamboa & 2 \\
\hline Molossus molossus & ROM-109045 & EF080477 & Guyana: Potaro-Siparuni & 8 \\
\hline Molossus molossus & ROM-104435 & ABECA137-06 & Ecuador: Napo, Parque Nacional Yasuni & 10 \\
\hline Molossus molossus & ROM-105514 & ABECA491-06 & Ecuador: Napo, Parque Nacional Yasuni & 9 \\
\hline Molossus molossus & ROM-113900 & BCBNT729-06 & Suriname: Brokopondo, Brownsberg Nature Park & 10 \\
\hline Molossus molossus & MHNG-1983.019 & KU737548 \& & French Guiana: Roura: Cacao & 4 \\
\hline Molossus molossus & MHNG-1984.008 & KU737550 $\S$ & French Guiana: Roura: Cacao & 11 \\
\hline Molossus molossus & Not preserved & KT721407 & Panama: Gamboa & 3 \\
\hline Molossus molossus & Not preserved & KT721409 & Panama: Gamboa & 4 \\
\hline Molossus rufus & ROM-108420 & EF080481 & Guyana: Potaro-Siparuni & 13 \\
\hline Molossus rufus & MHNG-1880.046 & KU737551 $\S$ & French Guiana: Régina:Nouragues & 12 \\
\hline Molossus sp. & ROM-109176 & EF080483 & Guyana: Potaro-Siparuni & 14 \\
\hline
\end{tabular}

\section{Figure captions}




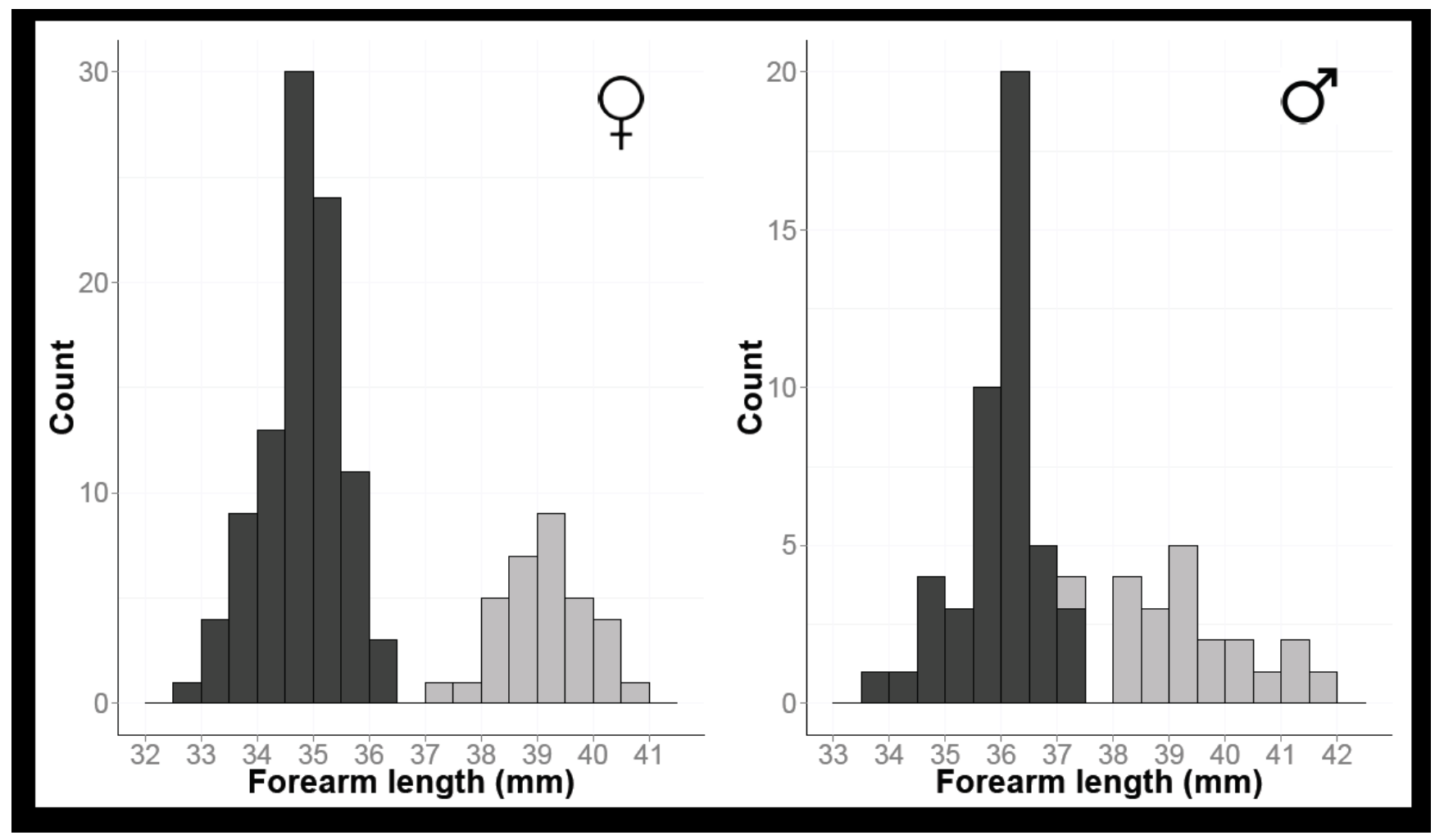

Figure 1. Distribution of forearm lengths for 128 females (left) and 68 males (right) of Molossus spp. caught in syntopy at two localities in French Guiana. The smaller animals correspond to the M. barnesi morphotype (represented in dark gray, FA smaller than 37.1 or $37.4 \mathrm{~mm}$ for females and males, respectively); the larger animals correspond to the M. molossus morphotype (represented in light gray, FA larger than 36.5 or $37.3 \mathrm{~mm}$ for females and males, respectively). 


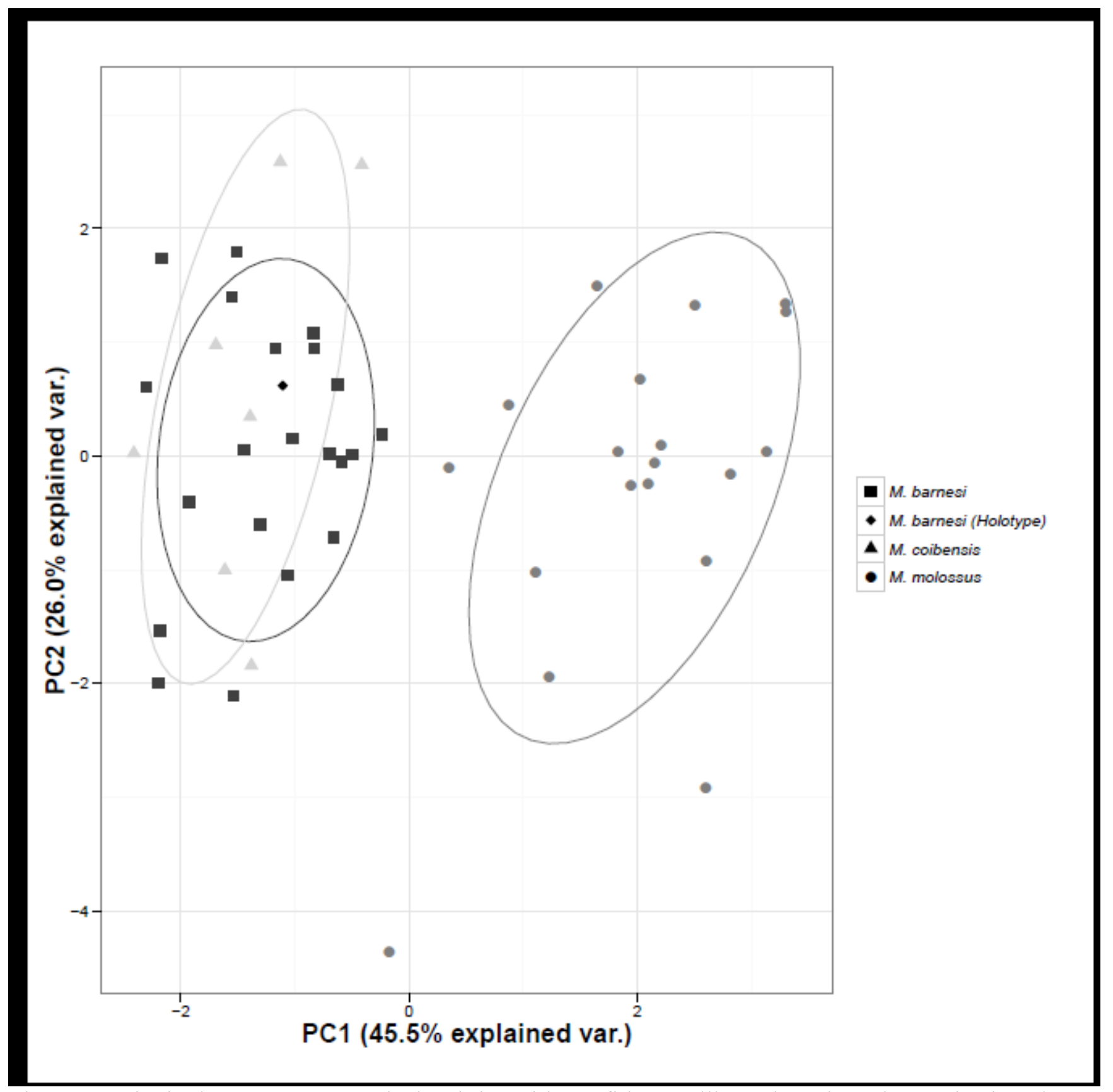

Figure 2. Principal Component Analysis Biplot with confidence ellipses based on six cranio-dental (GLS, CIL, MTL, BaM, BB, and PB) and one external (FA) measurements measured in 48 female specimens of Molossus spp. The legend for species is as follows: M. barnesi (black squares), $M$. coibensis (light gray point-up triangles) and M. molossus (gray circles). Notice the position of the holotype of $M$. barnesi (black diamond), which is placed in the middle of the groups including all $M$. barnesi from French Guiana and those of M. coibensis from Brazil. Specimens of M. molossus from French Guiana form a distinct cluster. The dataset comprises the holotype of M. barnesi (BMNH5.1.8.7), seven M. coibensis from Brazilian Para (Correa da Costa et al., 2013), 21 M. barnesi and 19 M. molossus from French Guiana (including 11 specimens studied by Simmons and Voss, 1998). Abbreviations: $\mathrm{PC}=$ Principal Component; var. $=$ variance. 


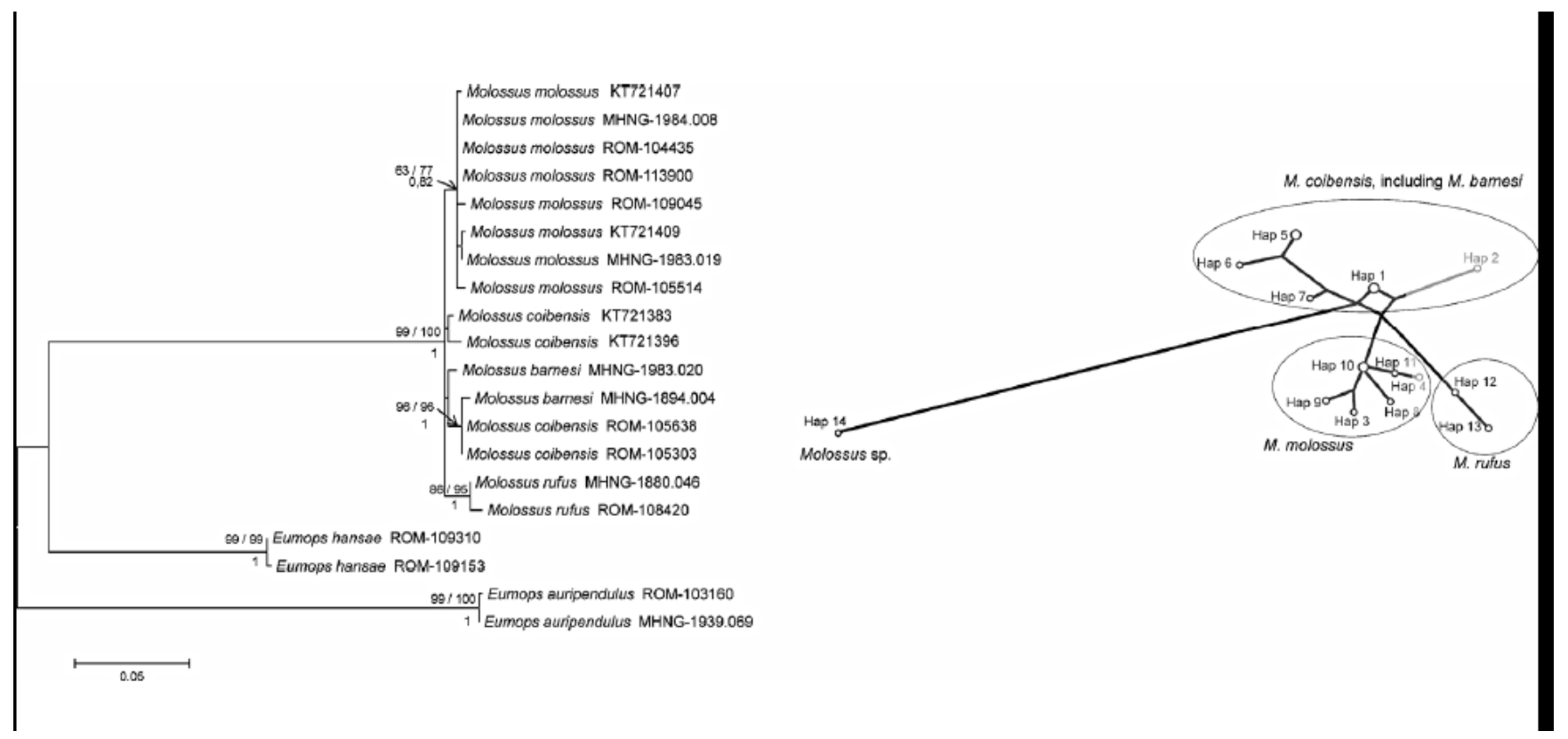

Figure 3.

Left: Maximum likelihood tree showing the phylogenetic relationships among $16 \mathrm{CO} 1$ barcodes of the following Molossus spp.: M. barnesi (French Guiana), M. coibensis (Ecuador, Panama), M. rufus (French Guiana; Guyana), and M. molossus (Ecuador, French Guiana, Guyana, Panama, Suriname). Each individual is identified with its voucher number (see details in the Appendix B). Bootstrap support from NJ / ML and posterior probabilities (PP) from a Bayesian analysis are shown above and below major nodes, respectively. The tree was rooted with sequences of Eumops hansae and E. auripendulus.

Right: Median-Joining network for 14 different CO1 haplotypes (Hap) of Molossus spp. (see Appendix B for linking haplotype number and specimen details). 

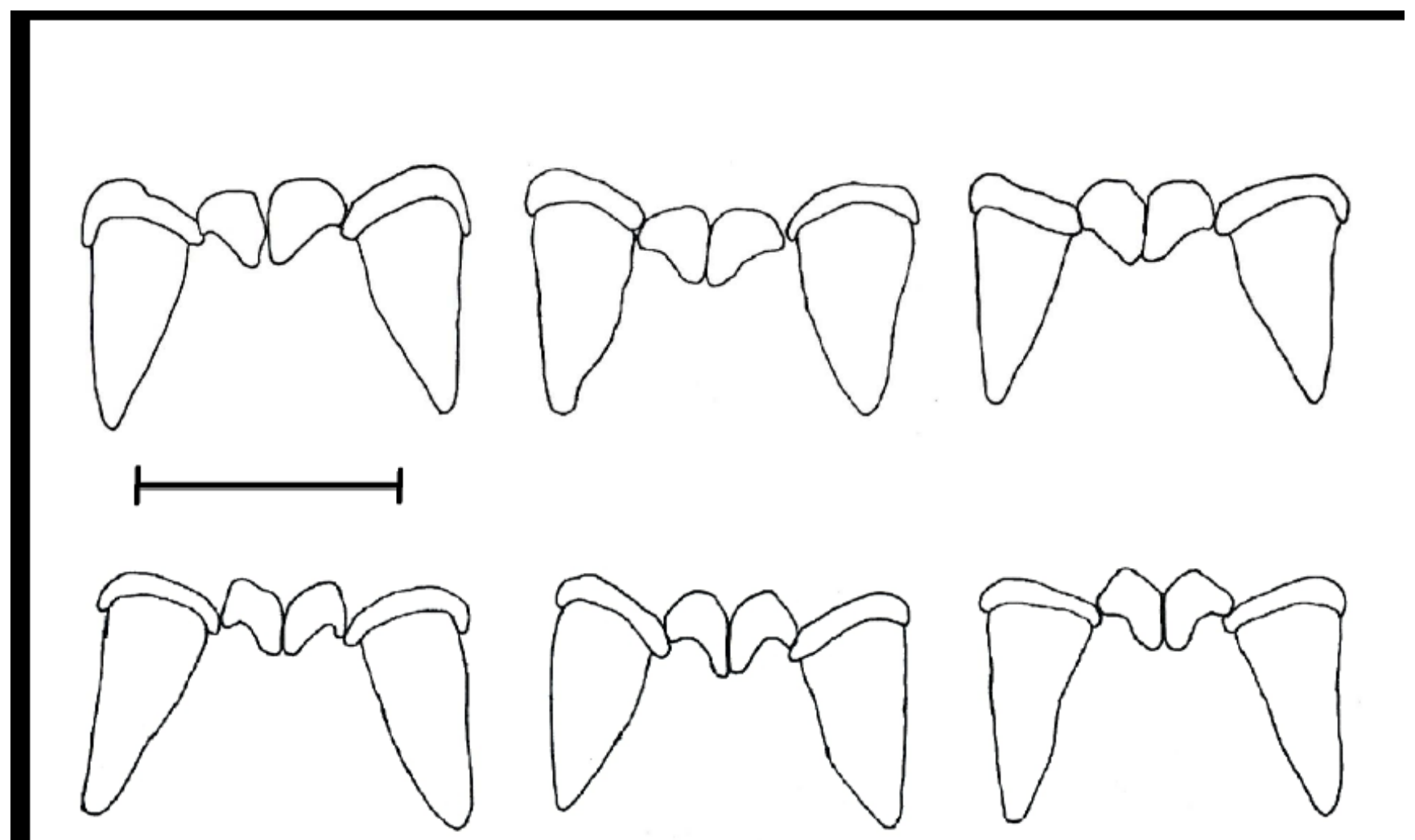

Figure 4. Frontal view of the upper dentition of three Molossus barnesi (top row) and three $M$.

molossus (bottom). The shape of upper incisors are more or less species-specific, i.e. more spatulate in M. barnesi (from left to right: MHNG-1979.023; 1979.026 and 1979.029) versus pincerlike in M. molossus (MHNG-1972.020, 1972.022 and 1972.023). The scale bar is $3.0 \mathrm{~mm}$. 